\title{
Arcanobacterium haemolyticum
}

National Cancer Institute

\section{Source}

National Cancer Institute. Arcanobacterium haemolyticum. NCI Thesaurus. Code C86149.

A species of facultatively anaerobic, Gram positive, rod shaped bacteria assigned to the phylum Actinobacteria. This bacteria is catalase negative, hemolytic on human blood agar plates and grows best in culture with added carbon dioxide and blood. A. haemolyticum is found on human skin and mucus membranes of the upper respiratory tract, and is associated with pharyng itis and skin and tissue infections. 